\title{
Intestinal Dysbiosis Exacerbates the Pathogenesis of Psoriasis-Like Phenotype Through Changes in Fatty Acid Metabolism
}

\section{Qixiang Zhao}

Sichuan University https://orcid.org/0000-0002-0306-9762

Jiadong Yu

Sichuan University

Hong Zhou

Sichuan University

Chen Zhang

Sichuan University

Xiaoyan Wang

Sichuan University

Jing Hu

Sichuan University

Yan Hao

Sichuan University

Yawen Hu

Sichuan University

Huaping Zheng

Sichuan University

Fanlian Zeng

Sichuan University

Chengcheng Yue

Sichuan University

Linna Gu

Sichuan University

Zhen Wang

Sichuan University

Fulei Zhao

Sichuan University

Pei Zhou

Sichuan University

Haozhou Zhang 
Sichuan University

\section{Nongyu Huang}

Sichuan University

\section{Wenling Wu}

Sichuan University

\section{Yifan Zhou}

Sichuan University

Jiong Li ( $\sim$ lijionghh@scu.edu.cn )

Sichuan University https://orcid.org/0000-0003-2320-9387

\section{Research}

Keywords: Psoriasis, intestinal microorganisms, intestinal microbiota, intestinal metabolites, fatty acid metabolism, fecal microbiota transplantation, co-housing, K14-VEGF, Th17,

Posted Date: November 16th, 2021

DOI: https://doi.org/10.21203/rs.3.rs-1067638/v1

License: (c) (1) This work is licensed under a Creative Commons Attribution 4.0 International License.

Read Full License 


\section{Abstract}

\section{Background}

The intestinal microbiota has been associated with host immunity, however, a link with psoriasis has not been demonstrated. Here, we sought to examine its role and mechanism of action in the pathogenesis of psoriasis.

\section{Results}

We performed co-housing and fecal microbial transplantation (FMT) experiments using the K14-VEGF transgenic mouse model of psoriasis. Psoriasis severity was accompanied with changes in the composition of the intestinal microbiota. Furthermore, FMT from mice with severe psoriasis exacerbated psoriasis in mice with mild symptoms, and increased the abundance of Prevotella, while decreasing that of Parabacteroides distasonis, in the colon. These alterations affected fatty acid metabolism, increasing the abundance of oleic and stearic acids. Indeed, oral administration of oleic and stearic acids exacerbated psoriasis and increased Th17 and monocyte-derived dendritic cell infiltration in the skin lesion areas.

\section{Conclusion}

Overall, our findings reveal that the intestinal microbiota modulates host metabolism and psoriasis pathogenesis in mice, suggesting a new target for the clinical diagnosis and treatment of psoriasis.

\section{Introduction}

Psoriasis is a skin-specific, immune-mediated disease that seriously endangers human health.(1) It affects approximately $2 \%$ of the population in Europe and North America, and there are more than 6 million psoriasis patients in China. $(2,3)$ The pathogenesis is mainly mediated by dendritic cells (DCs), T cells, and keratinocytes.(4) Among them, Th17 cells play an important role in the occurrence and development of psoriasis by producing IL-17A, which stimulates several responses that promote keratinocyte hyperproliferation, epidermal hyperplasia, and skin inflammation. $(5,6)$

Intestinal microorganisms are important factors affecting host health which influence the pathogenesis of immune-related diseases by regulating innate and adaptive immunity mediated by DCs, Th17 cells, epithelial cells, and goblet cells. $(7,8)$ Candidatus Arthromitus was reported to increase in the intestines of mice with autoimmune arthritis and it activated the differentiation of Th17 cells as well as induced autoimmune arthritis by promoting the secretion of serum amyloid A. $(9,10)$ However, the role and mechanism of intestinal microorganism in the regulation of psoriasis are still unclear.

Several studies examining differences in the composition of the intestinal microbiota between psoriasis patients and healthy controls have suggested that disorders of the intestinal microbiota may be closely related to the development of psoriasis. $(11,12)$ Moreover, germ-free (GF) mice develop more severe 
psoriasis-like skin inflammation than conventional mice due to enhanced Th17 responses, indicating that the intestinal microbiota may indeed be crucial in the progression of psoriasis(13). However, the link between specific intestinal microorganisms and psoriasis has not been systematically demonstrated, and the mechanism linking them has not been reported.

We observed that if mice with a mild pre-psoriatic phenotype are co-housed with severely psoriatic mice, their psoriatic pathogenesis is aggravated. Based on this observation and the recent studies linking the intestinal microbiota to psoriasis, we hypothesized that the development of psoriasis is mediated by the intestinal microbiota. Herein, we sought to examine this hypothesis. To that aim, we performed co-housing and fecal microbial transplantation (FMT) experiments using K14-VEGF transgenic mice, which develop an inflammatory condition resembling human psoriasis and are widely used as a model for studying psoriasis. $(14,15)$ We found that the intestinal microbiota of mice with a dramatic psoriasiform phenotype aggravated the psoriasis-like phenotype of mild pre-psoriatic mice. Furthermore, we demonstrate that the transfer of intestinal microbiota changed the composition of intestinal metabolites, and that increases in oleic acid and stearic acid content exacerbated the psoriatic phenotype through their effect on Th17 cells and DCs.

\section{Materials And Methods}

\section{Mice}

K14-VEGF mice (FVB-Tg [Krt14-Vegfa]3Dtm/J) were purchased from Jackson Laboratories (Catalogue no 005705). The mice were housed under the following controlled conditions: a steady temperature of $25 \pm 1^{\circ} \mathrm{C}$, a $12 \mathrm{~h}$ light $/ 12 \mathrm{~h}$ dark cycle, and free access to food and water. Littermates of the same sex

(female) were randomly assigned to experimental groups.

\section{H\&E staining}

Ear and colon tissue were fixed in $4 \%$ paraformaldehyde in PBS, embedded in paraffin, sectioned, and stained with H\&E for histopathologic examination. Images were captured using an Olympus BX600 microscope (Olympus Corporation, Tokyo, Japan) and a SPOT Flex camera (Olympus Corporation, Tokyo, Japan), and were analyzed with ImagePro Plus (version 6.0, Media Cybernetics) software. Epithelial thickness and cell infiltration were evaluated in independent regions. A pathological score based on the Baker score system was obtained to assess the severity of psoriasis in ear tissues.

\section{RT-qPCR analysis}

Total RNA from mice tissues was extracted with TRIzol agent (Thermo Fisher Scientific, 15596018) according to the manufacturer's protocol. Gel electrophoresis was performed to examine the integrity of the total RNA extracted. After the genomic DNA elimination reaction, the total RNA $(2 \mu \mathrm{g})$ was reverse 
transcribed into cDNA. A primeScript RT reagent kit with gDNA Eraser (Takara Bio, RR047A) was used for reverse transcription to produce $\mathrm{CDNA}$ at $37^{\circ} \mathrm{C}$ for $15 \mathrm{~min}$ and at $85^{\circ} \mathrm{C}$ for $5 \mathrm{~s}$ according to the manufacturer's protocol. The obtained cDNA (20 ng) was subjected to RT-qPCR analysis with TB Green ${ }^{\text {TM }}$ Premix Ex Taq ${ }^{T M}$ II (Takara Bio, RR820) according to the manufacturer's protocol. The results were normalized to beta-actin, and quantification was performed using the 2- $\Delta \Delta \mathrm{Ct}$ method. The melting curves ensured the amplification of a single product. All primers were obtained from Chengdu Qing Ke Zi Xi Biotechnology Co.

\section{S rRNA gene Microbiota Profiling}

Fecal samples were collected and stored at $-80^{\circ} \mathrm{C}$. Samples were prepared and analyzed by Beijing Genomics Institute, Inc. Bacterial genomic DNA was extracted from mouse fecal samples using PowerSoil Kit (MoBio, 12888-50). The V4 regions of 16S rRNA gene were PCR amplified using individually barcoded universal primers and $30 \mathrm{ng}$ of the extracted genomic DNA. The PCR reaction was set up in triplicate, and the PCR product was purified using Agencourt AMPure XP beads. The purified PCR product was pooled in equal molar concentrations, quantified by the Agilent 2100 Bioanalyzer, and sequenced using the HiSeq Illumina 2500 platform. OTUs were chosen by open-reference OTU picking based on $97 \%$ sequence similarity to the Greengenes 13_5 database. Taxonomy assignment and rarefaction were performed using QIIME1.8.0. for data analysis, including principal coordinates analysis and hierarchical clustering was performed using $\mathrm{R}$.

\section{AB-PAS staining}

Colon tissues were fixed in $4 \%$ paraformaldehyde in PBS, embedded in paraffin, sectioned, and stained with AB-PAS (Solarbio, G1285). Images of the sections were captured to count the number of goblet cells per crypt.

\section{Co-housing}

Three 2M K14-VEGF mice were co-housed three 6M K14-VEGF mice per cage. After four weeks of cohousing, mice were sacrificed to harvest the ear and colon tissue. Fecal samples were collected at the end of the co-housing period and stored at $-80^{\circ} \mathrm{C}$ for $16 \mathrm{~S}$ rRNA gene sequencing.

\section{Immunohistochemistry}

Colon tissues were fixed in $4 \%$ paraformaldehyde in PBS, and the fixed sections were incubated in $3 \%$ $\mathrm{H}_{2} \mathrm{O}_{2}$ solution in PBS at room temperature for $10 \mathrm{~min}$. Antigen retrieval was performed in sodium citrate buffer $(0.01 \mathrm{M}, \mathrm{pH} 6.0)$ in a microwave oven at $1000 \mathrm{~W}$ for $3 \mathrm{~min}$. Non-specific antibody binding was blocked by incubation with $5 \%$ normal goat serum in PBS for $1 \mathrm{~h}$ at $25^{\circ} \mathrm{C}$. Slides were stained overnight at 
$4{ }^{\circ} \mathrm{C}$ with anti-claudin-3 antibody (Invitrogen, 34-1700) and anti-CD45 antibody (BioLegend, 103102). The slides were subsequently washed and incubated with biotin-conjugated secondary antibodies for 30 min, and then with horseradish peroxidase streptavidin (HRP Streptavidin) for 30 min (SPlink Detection Kits; ZSGB-BIO, SP-9001 or SP-9002). The sections were developed using a 3,3'-Diaminobenzidine (DAB) substrate kit (ZSGB-BIO, ZLI-9017) and counterstained with hematoxylin. Images were captured using an Olympus BX600 microscope and a SPOT Flex camera. ImagePro Plus was used for further quantification of the $D A B$ intensity in the image.

\section{Fecal metabolomics}

Mice were fasted for $12 \mathrm{~h}$ and then fed for $4 \mathrm{~h}$. After that, fecal samples were collected, frozen in liquid nitrogen immediately, and stored at $-80^{\circ} \mathrm{C}$. Samples were prepared and analyzed in LC/MS platforms by Beijing Genomics Institute, Inc. In short, $100 \mu$ samples were extracted by directly adding $300 \mu \mathrm{l}$ of precooled methanol and acetonitrile (2:1, v/v), to which internal standards mix 1 (IS1) and internal standards mix 2 (IS2) were added for quality control of the sample preparation. After vortexing for $1 \mathrm{~min}$ and incubating at $-20^{\circ} \mathrm{C}$ for 2 hours, the samples were centrifuged for $20 \mathrm{~min}$ at $3000 \mathrm{~g}$, and the supernatant was then transferred for vacuum freeze drying. The metabolites were resuspended in $150 \mu \mathrm{l}$ of $50 \%$ methanol and centrifuged for $30 \mathrm{~min}$ at $4000 \mathrm{rpm}$, and the supernatants were transferred to autosampler vials for LC-MS analysis. A quality control (QC) sample was prepared by pooling the same volume of each sample to evaluate the reproducibility of the whole LC-MS analysis. The samples were analyzed on a Waters 2D UPLC (Waters, USA), coupled to a Q-Exactive mass spectrometer (Thermo Fisher Scientific, USA) with a heated electrospray ionization (HESI) source and controlled by the Xcalibur 2.3 software program (Thermo Fisher Scientific, Waltham, MA, USA). Chromatographic separation was performed on a Waters ACQUITY UPLC BEH C18 column $(1.7 \mu \mathrm{m}, 2.1 \mathrm{~mm} \times 100 \mathrm{~mm}$, Waters, USA), and the column temperature was maintained at $45^{\circ} \mathrm{C}$. The mobile phase consisted of $0.1 \%$ formic acid $(A)$ and acetonitrile (B) in the positive mode, and $10 \mathrm{mM}$ ammonium formate $(A)$ and acetonitrile $(B)$ in the negative mode. The gradient conditions were as follows: $0-1 \mathrm{~min}, 2 \% \mathrm{~B} ; 1-9 \mathrm{~min}, 2-98 \% \mathrm{~B} ; 9-12 \mathrm{~min}$, $98 \% \mathrm{~B} ; 12-12.1 \mathrm{~min}, 98 \% \mathrm{~B}$ to $2 \% \mathrm{~B}$; and $12.1-15 \mathrm{~min}, 2 \% \mathrm{~B}$. The flow rate was $0.35 \mathrm{ml} / \mathrm{min}$ and the injection volume was $5 \mu$ l.

The mass spectrometric settings for positive/negative ionization modes were as follows: spray voltage, 3.8/-3.2 kV; sheath gas flow rate, 40 arbitrary units (arb); aux gas flow rate, $10 \mathrm{arb}$; aux gas heater temperature, $350^{\circ} \mathrm{C}$; capillary temperature, $320^{\circ} \mathrm{C}$. The full scan range was $70-1050 \mathrm{~m} / \mathrm{z}$ with a resolution of 70000, and the automatic gain control (AGC) target for MS acquisition was set to $3 \mathrm{e} 6$ with a maximum ion injection time of $100 \mathrm{~ms}$. Top 3 precursors were selected for subsequent MSMS fragmentation with a maximum ion injection time of $50 \mathrm{~ms}$ and resolution of 17500, and the AGC was 1e5. The stepped normalized collision energy was set to 20,40 , and $60 \mathrm{eV}$. Data analysis, including principal component analysis and hierarchical clustering was performed using $\mathrm{R}$.

\section{Antibiotic Treatment}


Before FMT, mice were administered with antibiotics to reduce the intestinal microbiota. Mice were treated for five consecutive days with $200 \mu \mathrm{l}$ of an antibiotic cocktail (with each daily dose being administered by oral gavage after a $6 \mathrm{~h}$ fast) containing $1 \mathrm{~g} / \mathrm{l}$ ampicillin, $0.5 \mathrm{~g} / \mathrm{l}$ neomycin, $0.5 \mathrm{~g} / \mathrm{l}$ vancomycin, and $1 \mathrm{~g} / \mathrm{l}$ metronidazole. Fecal samples were collected before and after antibiotic treatment to verify the effect.

\section{Fecal Microbiota Transplantation}

After antibiotic treatment, a fecal slurry was obtained by pooling fecal pellets from $6-8$ donor mice (2 fresh feces pellets per mice). Feces pellets were resuspended with a vortex in $600 \mu$ l of reduced PBS (PBS with $0.5 \mathrm{~g} / \mathrm{l}$ cysteine and $0.2 \mathrm{~g} / / \mathrm{Na}_{2} \mathrm{~S}$ ) and then filtered through a $70 \mu \mathrm{m}$ cell strainer to remove insolubilized material. One hundred $\mu$ of supernatant was administered to each mice by oral gavage 3 times a week for two weeks. After this two-week period, mice received the microbiota suspension once a week until natural death or sacrifice.

\section{Preparation of single-cell suspensions}

Single-cell suspension preparation and flow cytometry were based on our previously published method. (16) Ear tissues were incubated for approximately $1.5 \mathrm{~h}$ at $37^{\circ} \mathrm{C}$ with $5 \mathrm{ml}$ of RPMI medium (Thermo Fisher Scientific, C22400500BT) containing $1 \mathrm{mg} / \mathrm{ml}$ of Collagenase type $\otimes$ (Gibco, 17100-017). Then, the tissues were minced with sharp scissors and incubated for an additional $15 \mathrm{~min}$ with $0.1 \mathrm{mg} / \mathrm{ml}$ DNase (Roche, 10104159001). Single-cell suspensions were made by mechanical dissociation with a gentleMACS dissociator (Miltenyi Biotech, Bergisch Gladbach, Germany) and filtered sequentially through $40 \mu \mathrm{m}$ and $70 \mu \mathrm{m}$ cell strainers (BD Bioscience, 352340 and 352350). Cells were washed once with PBS.

For DLNs, single-cell suspensions were harvested by pressing the tissues through a $70 \mu \mathrm{m}$ mesh in $5 \mathrm{ml}$ PBS.

For colonic lamina propria, the colon contents were first rinsed with precooled PBS. Then, $0.3 \mathrm{ml}$ of digestive solution 1 (1640 RPMI medium containing 5 mM EDTA, 1 mM DTT, and 5\% FBS) was added into a $1.5 \mathrm{ml}$ EP tube, and the colon tissue was cut into pieces. Then, the shredded colon tissue was transferred to a $15 \mathrm{ml}$ centrifuge tube containing $5 \mathrm{ml}$ of digestive solution 1 and shaken and incubated at $37^{\circ} \mathrm{C}$ for $30 \mathrm{~min}$. After mixing, the suspension was left to stand for $1 \mathrm{~min}$, the supernatant was discarded, and $6 \mathrm{~mL}$ of digestive solution 2 (1640 RPMI medium containing $0.2 \%$ type IV collagenase, $0.025 \%$ nuclease, and $5 \%$ FBS) was added. The mixture was shaken and incubated at $37{ }^{\circ} \mathrm{C}$ for $40-60 \mathrm{~min}$, during which the liquid pipette was gently blown every 20 min. Finally, the single cell suspension was filtered through a $70 \mu \mathrm{m}$ filter.

\section{Flow cytometry}


For surface staining, cells were stained with appropriate antibodies against surface antigens diluted in PBS on ice for $30 \mathrm{~min}$. Cellular viability was assessed by staining with 7-aminoactinomycin D (7-AAD) (BioLegend, 420404) to exclude dead cells. For the analysis of IL-17A production, in vitro re-stimulation and intracellular staining, single-cell suspensions were incubated for $4 \mathrm{~h}$ at $37^{\circ} \mathrm{C}$ with PMA (SigmaAldrich, p1585; $200 \mathrm{ng} / \mathrm{ml}$ ), brefeldin A (BioLegend, 420601; $5 \mu \mathrm{g} / \mathrm{ml}$ ), and ionomycin (Abcam, ab120116; $1 \mu \mathrm{g} / \mathrm{ml}$ ). The cells were then washed and stained with the fixable viability stain 620 (FVS 620-PE-Texas Red; BD-Biosciences, 564996) for 10 min. After performing surface staining as described above, cells were fixed with $4 \%$ paraformaldehyde and permeabilized with PBS supplemented with $0.1 \%$ Triton X-100. Intracellular staining with fluorescent-labeled antibodies was performed for $30 \mathrm{~min}$ in PBS. For flow cytometric analysis, the cells were washed and resuspended in PBS. Flow cytometry was performed using a NovoCyte flow cytometer and ACEA NovoExpress ${ }^{\text {TM }}$ software (ACEA Biosciences, San Diego, CA, USA), and a BD LSRFortessa flow cytometer and FlowJo TM10 software (BD, 647800L6). The single-cell suspensions were stained with the following antibodies: CD3-APC-CY7 (BioLegend, 100222), IL-17A-PE (BioLegend, 512305), CD4-PerCP-Cy5.5 (BioLegend, 100434), CD8-BV786 (BioLegend, 100750), CD45BV510 (BioLegend, 103138), CD11b-APC (BioLegend, 101212), MERTK-PE (BioLegend, 151506), MHCIIFITC (BioLegend, 107606), CD103-PE/Dazzle 594 (BioLegend, 121430), Ly6c-APC-Cy7 (BioLegend, 128026); PE-CD4 (BioLegend, 100408), FITC-CD3 (BioLegend, 100204), IL-17-PerCP (BioLegend, 505920), CD8-APC-CY7 (BioLegend, 344714). Antibodies were used at 1:100 dilution.

\section{Supplementation with oleic acid and stearic acid}

Mice were gavaged with oleic acid $(50 \mathrm{mg} / \mathrm{ml})$ and stearic acid $(20 \mathrm{mg} / \mathrm{ml})$ in PBS according to body wight $(10 \mu \mathrm{l} / \mathrm{g})$. After supplementation with oleic acid and stearic acid for 41 days, mice were sacrificed to harvest the ear and DLN, and flow cytometry was performed to detect Th17 cells and DCs.

\section{Statistical analysis}

Statistical details are provided in the figure legends, the Results section, and the STAR Methods section. All statistical analysis was performed with GraphPad Prism 8 software (GraphPad Software Company, version 8.0.0). Student's t-test was used for comparing the groups. $P<0.05$ was considered statistically significant.

\section{Results}

\section{Psoriasis severity increases with age in K14-VEGF transgenic mice, and this is accompanied with changes in the composition of the intestinal microbiota}


First, we found that 6-month-old K14-VEGF (6M) mice had a significantly more severe course of the disease than 2-month-old (2M) mice (Figure S1A). In addition, the Psoriasis Area and Severity Index (PASI) score of $6 \mathrm{M}$ mice was higher than that of $2 \mathrm{M}$ mice (Figure $1 \mathrm{~A}$ ). Histological examination of ear sections stained with hematoxylin and eosin (H\&E) revealed the severity of the disease in $2 \mathrm{M}$ and $6 \mathrm{M}$ mice (Figure S1B). Based on the Baker scoring system, 6M mice exhibited a higher score (Figure 1B) and thicker epidermis (Figure S1C) than 2M mice. Furthermore, 6M mice had higher IL-17 mRNA levels in the ear than $2 \mathrm{M}$ mice (Figure 1C).

Second, we found that the increase in the severity of the disease was accompanied with differences in the composition of the intestinal microbiota between $2 \mathrm{M}$ and $6 \mathrm{M}$ mice (Figure 1F); however, total species diversity and the observed species were not significantly different between $2 \mathrm{M}$ and $6 \mathrm{M}$ mice (Figure 1D and 1E). We found that, whilethe abundance of Prevotella was higher in 6M mice, that of Parabacteroides distasonis was higher in $2 \mathrm{M}$ mice (Figure $1 \mathrm{G}$ and $1 \mathrm{H}$ ). These results were verified by qPCR (Figure $1 \mathrm{I}$ and $1 \mathrm{~J})$.

The number of colonic goblet cells and mucus content are correlated with the colonization rate of some microorganisms. For example, colonization by Akkermansia muciniphila increases the thickness of the intestinal mucus layer, $(17,18)$ and its abundance is positively correlated with the number of goblet cells and the expression of mucin 2 (Muc-2).(19) Similarly, Prevotella is an intestinal microbe that colonizes the mucus layer of mammals and uses mucus as a source of nitrogen and carbon. $(20,21)$ Here, histological staining with Alcian Blue (AB)-Periodic Acid Schiff (PAS) revealed that the number of colonic mucussecreting goblet cells in $6 \mathrm{M}$ mice was significantly higher than that in $2 \mathrm{M}$ mice (Figure S1D and S1E). In addition, 6M mice had higher Muc-2 mRNA levels in the colon (Figure S1F). These results suggested that higher Muc-2 expression in 6M mice may lead to an increased colonization by Prevotella.

\section{Co-housing with 6M mice exacerbated psoriasis in, and changed the intestinal microbiota composition of, $2 \mathrm{M}$ mice.}

Next, we performed co-housing experiments and found that, compared with separately housed 2M (Sep$2 \mathrm{M}$ ) mice, co-housed $2 \mathrm{M}$ (Co-2M, co-housed with $6 \mathrm{M}$ mice) mice had more severe psoriasis after four weeks (Figure 2A). The PASI score of Co-2M mice was already increased after co-housing for two weeks and significantly increased after three weeks compared with Sep-2M mice (Figure 2B). After co-housing, ear sections were stained with H\&E (Figure 2C). Co-2M mice showed a higher Baker score and thicker epidermis than Sep-2M mice (Figure 2D and 2E). Meanwhile, compared with Sep-2M mice, Co-2M mice showed higher IL-17 mRNA expression in the ear (Figure 2F).

In addition, co-housing changed the composition of the intestinal microbiota in Co-2M mice. 16S rRNA gene sequencing showed that compared with Sep-2M mice, Co-2M mice exhibited an increase in total species diversity and observed species (Figure $2 \mathrm{G}$ and $2 \mathrm{H}$ ). Furthermore, the operational taxonomic units (OTUs) in Co-2M mice were more similar to those in 6M mice than those in Sep-2M mice (Figure 2I). In terms of $\beta$-diversity, Co-2M and 6M mice showed similar intestinal microbiota composition, which was 
markedly distinct from that of Sep-2M mice (Figure 2J). In addition, the abundance of Prevotella was increased, while that of Parabacteroides distasonis was decreased, in Co-2M mice after co-housing (Figure $2 \mathrm{~K}$ and $2 \mathrm{~L}$ ). The $\mathrm{qPCR}$ results showed that the relative abundance of Prevotella was increased in the fecal samples of Co-2M mice, while that of Parabacteroides distasonis was decreased, after cohousing (Figure $2 \mathrm{M}$ and $2 \mathrm{~N}$ ). These results suggested that the intestinal microorganisms from mice with severe psoriasis may exacerbate psoriasis in mice with mild symptoms.

Disorders of the intestinal microbiota are related to intestinal inflammation. $(22,23)$ To explore the potential mechanisms whereby the intestinal microbiota may influence psoriasis, we studied the barrier, absorptive function, and inflammation of the intestines in mice. The length of the colon, histological score, and villus length in $2 \mathrm{M}$ and $6 \mathrm{M}$ mice were not statistically significantly different (Figure S2A-S2D). Immunohistochemistry (IHC) was performed to examine the number of immune cells in the colon, and no significant differences in the number of $\mathrm{CD} 45^{+}$cells (immune cells) were found between $2 \mathrm{M}$ and $6 \mathrm{M}$ mice (Figure S2E and S2F). Moreover, 2M and 6M mice showed no significant differences in the colonic mRNA expression of IL-17A (Figure S2G).

Intestinal microorganisms have been reported to prevent deterioration caused by hepatic injury and reduce neutrophil infiltration in the liver by enhancing the integrity of the intestinal epithelial barrier and increasing the expression of claudin-3, a tight junction integrin closely related to the integrity of the intestinal epithelium; $(24,25)$ therefore, $I \mathrm{HC}$ was performed to examine the colonic expression of claudin-3. No significant differences were found between $2 \mathrm{M}$ and $6 \mathrm{M}$ mice (Figure S2H and S2I).

\section{Co-housing with $6 \mathrm{M}$ mice changed the intestinal metabolite composition and metabolic pathways of $2 \mathrm{M}$ mice.}

The intestinal microbiota was reported to regulate amino acid metabolism in the intestines, thereby inhibiting Alzheimer's disease progression.(26) Thus, we hypothesized that the intestinal metabolites resulting from microbial metabolism have an impact on psoriasis susceptibility. We utilized metabolomic profiling to identify candidate microbiota-dependent molecules in fecal samples of $6 \mathrm{M}, \mathrm{Co}-2 \mathrm{M}$, and Sep$2 \mathrm{M}$ mice in the co-housing experiment as previously mentioned. (Figure S3A). After co-housing, the intestinal metabolite composition of Co-2M mice was similar to that of $6 \mathrm{M}$ mice (Figure $3 \mathrm{~A}$ ). A heatmap of metabolites and a volcano plot revealed similar metabolite abundance in Co-2M and 6M mice (Figure 3B and $3 \mathrm{C}$ ). Pathway enrichment analysis showed differences in a-linolenic acid metabolism and fatty acid biosynthesis between Sep-2M and 6M mice, and between Sep-2M and Co-2M mice (Figure 3D and $3 \mathrm{E})$. Moreover, the relative abundances of oleic acid and linoleic acid were higher in $6 \mathrm{M}$ and Co-2M mice (Figure 4F and 4G), while traumatic acid was higher in Sep-2M mice (Figure S3B). These data indicated that intestinal microbiota-derived changes in fatty acid metabolism may play a role in the development of psoriasis. 


\section{Fecal microbiota transplantation from $6 \mathrm{M}$ to $2 \mathrm{M}$ mice significantly exacerbated psoriasis and increased the infiltration of Th17 cells into the ear.}

FMT is an effective method for intestinal microbial colonization. $(17,26)$ To certain that microbes from the intestine regulated the progression of the psoriasis, FMT was performed. Here, we divided $2 \mathrm{M}$ mice into transplanted and control groups, and treated them with a cocktail of antibiotics to reduce their intestinal microbiota. Then, mice in the transplanted group were gavaged with a fecal microbiota filtrate from 6M mice (donor mice), while control mice were gavaged with reduced PBS instead (Figure 4A). After colonization for two months, the severity of ear psoriasis in the transplanted group was significantly higher than that in the control group (Figure 4B). In addition, the PASI of transplanted mice was significantly higher than that of control mice (Figure 4C). After FMT, mice were sacrificed and ear sections were stained with H\&E (Figure 4D). Histological photographs of the ear showed higher Baker score and thicker epidermis in the transplanted group than in the control group (Figure 4E and 4F). Furthermore, we examined the infiltration of T cells and Th17 cells using flow cytometry (Figure 4G). Transplanted mice showed higher T cell and Th17 cell infiltration in the ear than control mice (Figure 4H and 4I). However, there were no significant differences between transplanted and control mice in terms of immune cell infiltration in the colonic lamina propria (Figure $4 \mathrm{~J}$ and $4 \mathrm{~K}$ ).

\section{FMT from 6M mice significantly altered the intestinal microbial composition of $2 \mathrm{M}$ mice.}

After antibiotic treatment, the number of species detected in the intestines of mice in the transplanted and control groups decreased significantly (Figure S4A and S4B). After FMT, species abundance and diversity in transplanted mice were significantly higher than those in control mice (Figure 5A and 5B). Moreover, transplanted mice shared more OTUs with donor mice than with control mice (Figure 5C). The intestinal microbial composition of transplanted mice was remarkably similar to that of donor mice and significantly different from that of control mice (Figure 5D). Furthermore, the abundances of Saccharibacteria, Alloprevotella rava, Alistipes onderdonkii, Prevotella copri,and Bacteroides acidifaciens were increased in transplanted mice (Figure 5E-5J). This in turn suppressed colonization by Parabacteroides distasonis (Figure 5K).

\section{Fecal microbial transplantation from donor mice altered the intestinal metabolic composition and metabolic pathways of transplanted mice}

To examine whether the intestinal microbiota from psoriatic mice mediated the aggravation of psoriasis by regulating intestinal fatty acid metabolism, we analyzed the intestinal metabolism of mice in the FMT 
experiment as previously mentioned. (Figure S5A). The intestinal metabolite composition of transplanted mice was similar to that of donor mice and different from that of control mice (Figure 6A). A volcano plot revealed lower differential abundance of metabolites between transplanted and donor mice (Figure 6C). In addition, similar to the results of the co-housing experiments, the a-linoleic acid metabolism pathway was different between donor and control mice as well as between transplanted and control mice (Figure 6D and $6 \mathrm{E}$ ). The abundance of stearic acid and linoleic acid was higher in transplanted mice (Figure 6F and $6 \mathrm{G})$, while that of traumatic acid was higher in control mice (Figure S6B).

\section{Administration of free fatty acids aggravated psoriasis in K14-VEGF mice by increasing the differentiation of Th17 cells in draining lymph nodes (DLNs), and the infiltration of monocyte-derived DCs (moDDCs) and Th17 cells into the ear.}

Oleic acid and palmitic acid were reported to activate DCs, stimulate IL-23 secretion, enhance Th17 cell responses, and increase IL-17 expression in vitro.(27) $2 \mathrm{M}$ mice were administered with either oleic and stearic acids (treated group) or PBS (control group). After 41 days of gavage, we found that oleic and stearic acid administration aggravated psoriasis, as evidenced by the swelling and scaling of the ear (Figure S6A). The treated group had a significantly higher PASI score than the control group (Figure 7A). The ear was stained with H\&E (Figure 7B) and the Baker score showed that the treated group had significantly more severe psoriasis than control mice (Figure 7C) and that the epidermis was significantly thickened (Figure S6B).

Flow cytometry was performed to examine Th17 cell differentiation in DLNs of the three groups (Figure 7D). The results showed that, compared with control mice, Th17 cell differentiation was increased in the treated group (Figure 7E). Furthermore, Th17 cell infiltration into the ear was also detected by flow cytometry (Figure 7F), and the results demonstrated an increase in the treated groups (Figure 7G).

IL-23 production by DCs is required for the differentiation, expansion, and survival of pathogenic Th17 cells.(28-30) Therefore, we examined DC infiltration (Figure S6D). The results showed that the numbers of monocytes and moDDCs were significantly increased in the ears of treated mice (Figure $7 \mathrm{H}-7 \mathrm{~J}$ ). MoDDCs were reported to mediate imiquimod (IMQ)-induced psoriasis-like keratinocyte proliferation, thickening of epidermis, and dermal inflammation.(31) In addition, the expression of IL-23 was increased in treated mice (Figure 7K). Together, our results suggested that intestinal microbiota-derived increases in oleic and stearic acid levels sensitized DCs, increasing IL-23 expression and Th17 infiltration into the ear, thus exacerbating the pathogenesis of psoriasis.

\section{Discussion}


Psoriasis is a skin-specific, immune-mediated disease that is mainly mediated by DCs, Th17 cells, and keratinocytes. Several studies have suggested that intestinal dysbiosis may be closely related to the development of immune-mediated diseases. However, a link with psoriasis has not been systematically demonstrated, and the mechanism whereby the intestinal microbiota may mediate psoriasis progression remains unknown. Therefore, we sought to investigate the role of the intestinal microbiota and its mechanism of action in the pathogenesis of psoriasis. To these aims, we employed the widely used K14VEGF transgenic mouse model of psoriasis, and performed co-housing and fecal microbial transplantation experiments.

In examining the aspects mentioned above, we found that psoriasis severity in K14-VEGF mice is accompanied with changes in the intestinal microbiota. Prevotella abundance was high in the intestines of mice with severe psoriasis, while the abundance of Parabacteroides distasonis was high in mice with mild psoriasis. In addition, we found that co-housing and FMT exacerbates psoriasis symptoms in mice with mild psoriasis, including ear inflammation, IL-17 expression, and Th17 infiltration. Moreover, this was associated with an increase in Prevotella abundance and a decline in the abundance of Parabacteroides distasonis in the colon. Moreover, mice with severe psoriasis showed high IL-17A expression in the ear and high Muc-2 expression in the colon as well as increased numbers of mucus-secreting goblet cells. Furthermore, the changes in the intestinal microbiota disturbed the metabolic composition of the colon because fatty acid metabolism, including the a-linolenic acid metabolic pathway, was altered. Specifically, we found that the changes in the microbiota resulted in an increase in the abundance of colonic oleic, linoleic, and stearic acids, and a decrease in the abundance of traumatic acid. In turn, these changes aggravated psoriasis in K14-VEGF mice. To confirm the role of fatty acid metabolism disturbance in the progression of psoriasis, we administered oleic and stearic acids to K14-VEGF mice, and found that this aggravated psoriasis by increasing Th17 cell differentiation in DLNs of the ear as well as Th17 and moDDC infiltration in the ear.

It has been reported that, compared with healthy patients, the abundance of Prevotella in the intestines of patients with psoriasis is increased, while that of the Porphyromonadaceae family, to which Parabacteroides distasonis belongs, is decreased $(32,33)$. Thus, our findings suggest that the intestinal microbiota plays an important role in the progression of psoriasis.

The intestinal mucus barrier is an important barrier for host resistance to external infection, and it is the main place where intestinal microorganisms co-exist with host cells. IL-17 has been reported to stimulate the trachea to secrete more mucus through the IL-6 paracrine/autocrine loop.(34) Prevotella colonizes the mucus layer of mammals and can use mucus as a source of nitrogen and carbon. Thus, increased mucus production may explain the higher abundance of Prevotella in the intestines of mice with severe psoriasis.

Parabacteroides was reported to protect against the progression of seizures by modulating amino acid metabolism in the intestines and brain.(35) Moreover, Parabacteroides distasonis was shown to reduce abnormal lipid metabolism and obesity by increasing the production of intestinal cholic acid(36). Thus, our results suggest that the reduction in the abundance of Parabacteroides leads to disturbances in intestinal fatty acid metabolism, which results in increased levels of certain intestinal fatty acids, such as 
oleic, stearic, and linoleic acids, thereby exacerbating psoriasis. In addition, traumatic acid, a medium and long-chain fatty acid secreted by plants when damaged, has been reported to repair skin damage.(37, 38) Thus, the reduction in the levels of microbiota-derived traumatic acid that we have observed may also play an important role in psoriasis development.

Psoriasis, obesity, and other metabolic abnormalities may be closely related. A clinical study involving 35,000 participants showed that metabolic syndrome is associated with an increased risk of psoriasis. (39) An analysis of the metabolic factors showed that obesity was the central factor in this association. Moreover, epidemiological studies have provided strong evidence suggesting that obesity and weight gain are risk factors for psoriasis(40). Nakamizo and colleagues found that the accumulation of IL-17Aproducing $\gamma \delta T$ cells in psoriatic lesions of high-fat-diet-induced obese mice leads to aggravation of psoriatic dermatitis. Palmitic acid and oleic acid can sensitize DCs, thus enhancing Th17 cell responses and promoting the secretion of IL-17, IL-22, and other pro-inflammatory cytokines. Furthermore, mice fed a high-fat diet containing oleic acid, stearic acid, and linoleic acid showed worsened IMQ-induced, Th1/Th17-driven psoriatic dermatitis. Furthermore, serum total free fatty acids such as palmitic acid and oleic acid were closely related to the severity of skin inflammation.

Psoriasis is an autoimmune disease that seriously endangers human health for which there is no affordable and effective treatment. $(41,42)$ To develop better treatments, the pathogenesis of psoriasis must be urgently explored. As the second genome of the human body, the intestinal microbiome, which is composed of many species, has great potential for exploitation(43). Lactococcus lactis synthesizes vitamin $\mathrm{K}_{2}$, which cannot be synthesized by the human body, and is therefore transplanted to patients with vitamin $\mathrm{K}$ deficiency.(44) In addition, oral administration of Akkermansia muciniphila has been shown to decrease body weight and the levels of blood markers related to liver dysfunction in overweight and obese humans.(45) Thus, the administration of intestinal microorganisms has valuable clinical applications for the treatment of several diseases, including psoriasis.

\section{Conclusion}

In conclusion, our study investigated the relationship between the intestinal microbial composition and pathogenesis of psoriasis in mice, and through metabolomics demonstrated the mechanism whereby intestinal microorganisms may affect the development of psoriasis. Our results indicate that altered intestinal microbial composition and abnormal fatty acid metabolism may play a key role in the pathogenesis of psoriasis, thus suggesting a new target for the clinical diagnosis and treatment of psoriasis.

\section{Abbreviations}

FMT: Fecal microbial transplantation 
DCs: Dendritic cells

GF: Germ-free

DLNs: Draining lymph nodes

PASI: Psoriasis Area and Severity Index

6M: 6-month-old

2M: 2-month-old

Sep-: Separately housed

Co-: Co-housed

H\&E: Hematoxylin and eosin

Muc-2: Mucin 2

AB-PAS: Alcian Blue-Periodic Acid Schiff

OUTs: Operational taxonomic units

IHC: Immunohistochemistry

moDDCs: Monocyte-derived DCs

IMQ: Imiquimod

PcoA: Principal co-ordinates analysis

PCA: Principal component analysis

LDA: Linear discriminant analysis

LEfSe: Linear discriminant analysis effect size

\section{Declarations}

\section{Ethics approval and consent to participate}

The animal protocols were approved by the Committee on the Ethics of Animal Experiments of Sichuan University. The experimental procedures were conducted according to the ethical guidelines for the care and use of laboratory animals of the National Institutes of Health (https://grants.nih.gov/grants/olaw/guide-for-the-care-and-use-of-laboratory-animals.pdf) and the 
International Association for the Study of Pain (IASP). Every effort was made to decrease the number of animals used and to reduce animal suffering.

\section{Consent for publication}

Not applicable.

\section{Data availability statement}

The data that support the findings of this study are openly available in [NCBI-SRA] at [https://dataview.ncbi.nlm.nih.gov/object/PRJNA771247?

reviewer=40enahaki9tr9t1 qs1aacpp7m9] and [https://www.ncbi.nlm.nih.gov/bioproject/770517] reference number [PRJNA771247 and 770517].

\section{Competing interests}

The authors declare no competing interests.

\section{Funding}

This work was supported by the National Natural Science Foundation of China $(31271483,81472650$, 81673061, 81573050, 31872739, and 81703132), the National Science and Technology Major Project (2018ZX09733001-001-006 and 2019ZX09201003-003), and the Sichuan Provincial Outstanding Youth Fund (2015JQ0025).

\section{Author Contributions}

Q. Z. and J. L. designed the experiments and wrote the manuscript. Q. Z. performed data analyses. Q.Z. and J. Y. performed the co-housing and FMT experiments. Q. Z. and J. Y. performed 16S rRNA gene sequencing data collection and analysis. Q. Z., J. Y., H. Z., L. G., C. Z., Haozhou Zhang, Huaping Zheng, X. W., F. Z., J. H., Yan Hao, and Yawen Hu performed flow cytometry. Q. Z., J. Y., and C. Y. performed the histological experiments. J. Y., H. Z., and Y. Z. took the pictures of the ears. Q. Z., N. H., Z. W., and W. W. performed the RT-qPCR experiments.

\section{Acknowledgments}

We thank Shangwei $\mathrm{Xu}$, who is an illustrator, for his exquisite work on the graphical abstract. 


\section{References}

1. Boehncke WH, Schon MP. 2015. Psoriasis. Lancet 386:983-94. http://dx.doi.org/10.1016/S01406736(14)61909-7

2. Christophers E. 2001. Psoriasis-epidemiology and clinical spectrum. Clin Exp Dermatol 26:314-20. http://dx.doi.org/10.1046/j.1365-2230.2001.00832.x

3. Ding X, Wang T, Shen Y, Wang X, Zhou C, Tian S, Liu Y, Peng G, Zhou J, Xue S, Wang R, Tang Y, Meng X, Pei G, Bai Y, Liu Q, Li H, Zhang J. 2012. Prevalence of psoriasis in China: a population-based study in six cities. Eur J Dermatol 22:663-7. http://dx.doi.org/10.1684/ejd.2012.1802

4. Nestle FO, Kaplan DH, Barker J. 2009. Psoriasis. N Engl J Med 361:496-509. http://dx.doi.org/10.1056/NEJMra0804595

5. Cai Y, Fleming C, Yan J. 2012. New insights of T cells in the pathogenesis of psoriasis. Cell Mol Immunol 9:302-9. http://dx.doi.org/10.1038/cmi.2012.15

6. Di Cesare A, Di Meglio P, Nestle FO. 2009. The IL-23/Th17 axis in the immunopathogenesis of psoriasis. J Invest Dermatol 129:1339-50. http://dx.doi.org/10.1038/jid.2009.59

7. Thaiss CA, Zmora N, Levy M, Elinav E. 2016. The microbiome and innate immunity. Nature 535:65-74. http://dx.doi.org/10.1038/nature18847

8. Honda K, Littman DR. 2016. The microbiota in adaptive immune homeostasis and disease. Nature 535:75-84. http://dx.doi.org/10.1038/nature18848

9. Wu HJ, Ivanov, II, Darce J, Hattori K, Shima T, Umesaki Y, Littman DR, Benoist C, Mathis D. 2010. Gutresiding segmented filamentous bacteria drive autoimmune arthritis via T helper 17 cells. Immunity 32:815-27. http://dx.doi.org/10.1016/j.immuni.2010.06.001

10. Ivanov, II, Atarashi K, Manel N, Brodie EL, Shima T, Karaoz U, Wei D, Goldfarb KC, Santee CA, Lynch SV, Tanoue T, Imaoka A, Itoh K, Takeda K, Umesaki Y, Honda K, Littman DR. 2009. Induction of intestinal Th17 cells by segmented filamentous bacteria. Cell 139:485-98.

http://dx.doi.org/10.1016/j.cell.2009.09.033

11. Hidalgo-Cantabrana C, Gomez J, Delgado S, Requena-Lopez S, Queiro-Silva R, Margolles A, Coto E, Sanchez B, Coto-Segura P. 2019. Gut microbiota dysbiosis in a cohort of patients with psoriasis. Br J Dermatol 181:1287-1295. http://dx.doi.org/10.1111/bjd.17931

12. Codoner FM, Ramirez-Bosca A, Climent E, Carrion-Gutierrez M, Guerrero M, Perez-Orquin JM, Horga de la Parte J, Genoves S, Ramon D, Navarro-Lopez V, Chenoll E. 2018. Gut microbial composition in patients with psoriasis. Sci Rep 8:3812. http://dx.doi.org/10.1038/s41598-018-22125-y

13. Zakostelska Z, Malkova J, Klimesova K, Rossmann P, Hornova M, Novosadova I, Stehlikova Z, Kostovcik M, Hudcovic T, Stepankova R, Juzlova K, Hercogova J, Tlaskalova-Hogenova H, Kverka M. 2016. Intestinal Microbiota Promotes Psoriasis-Like Skin Inflammation by Enhancing Th17 Response. PLoS One 11:e0159539. http://dx.doi.org/10.1371/journal.pone.0159539

14. Xia YP, Li B, Hylton D, Detmar M, Yancopoulos GD, Rudge JS. 2003. Transgenic delivery of VEGF to mouse skin leads to an inflammatory condition resembling human psoriasis. Blood 102:161-8. 
http://dx.doi.org/10.1182/blood-2002-12-3793

15. Huggenberger R, Ullmann S, Proulx ST, Pytowski B, Alitalo K, Detmar M. 2010. Stimulation of lymphangiogenesis via VEGFR-3 inhibits chronic skin inflammation. J Exp Med 207:2255-69. http://dx.doi.org/10.1084/jem.20100559

16. Wang Z, Zhou H, Zheng H, Zhou X, Shen G, Teng X, Liu X, Zhang J, Wei X, Hu Z, Zeng F, Hu Y, Hu J, Wang X, Chen S, Cheng J, Zhang C, Gui Y, Zou S, Hao Y, Zhao Q, Wu W, Zhou Y, Cui K, Huang N, Wei Y, Li W, Li J. 2021. Autophagy-based unconventional secretion of HMGB1 by keratinocytes plays a pivotal role in psoriatic skin in fl ammation. Autophagy 17:529-552. http://dx.doi.org/10.1080/15548627.2020.1725381

17. Barcena C, Valdes-Mas R, Mayoral P, Garabaya C, Durand S, Rodriguez F, Fernandez-Garcia MT, Salazar N, Nogacka AM, Garatachea N, Bossut N, Aprahamian F, Lucia A, Kroemer G, Freije JMP, Quiros PM, Lopez-Otin C. 2019. Healthspan and lifespan extension by fecal microbiota transplantation into progeroid mice. Nat Med 25:1234-1242. http://dx.doi.org/10.1038/s41591-0190504-5

18. van Beek AA, Sovran B, Hugenholtz F, Meijer B, Hoogerland JA, Mihailova V, van der Ploeg C, Belzer C, Boekschoten MV, Hoeijmakers JH, Vermeij WP, de Vos P, Wells JM, Leenen PJ, Nicoletti C, Hendriks RW, Savelkoul HF. 2016. Supplementation with Lactobacillus plantarum WCFS1 Prevents Decline of Mucus Barrier in Colon of Accelerated Aging Ercc1(-/Delta7) Mice. Front Immunol 7:408. http://dx.doi.org/10.3389/fimmu.2016.00408

19. Giannoudaki E, Hernandez-Santana YE, Mulfaul K, Doyle SL, Hams E, Fallon PG, Mat A, O'Shea D, Kopf M, Hogan AE, Walsh PT. 2019. Interleukin-36 cytokines alter the intestinal microbiome and can protect against obesity and metabolic dysfunction. Nat Commun 10:4003. http://dx.doi.org/10.1038/s41467-019-11944-w

20. Amat S, Lantz H, Munyaka PM, Willing BP. 2020. Prevotella in Pigs: The Positive and Negative Associations with Production and Health. Microorganisms 8. http://dx.doi.org/10.3390/microorganisms8101584

21. Wright DP, Rosendale DI, Robertson AM. 2000. Prevotella enzymes involved in mucin oligosaccharide degradation and evidence for a small operon of genes expressed during growth on mucin. FEMS Microbiol Lett 190:73-9. http://dx.doi.org/10.1111/j.1574-6968.2000.tb09265.x

22. Earley H, Lennon G, Balfe A, Coffey JC, Winter DC, O'Connell PR. 2019. The abundance of Akkermansia muciniphila and its relationship with sulphated colonic mucins in health and ulcerative colitis. Sci Rep 9:15683. http://dx.doi.org/10.1038/s41598-019-51878-3

23. Burrello C, Garavaglia F, Cribiu FM, Ercoli G, Lopez G, Troisi J, Colucci A, Guglietta S, Carloni S, Guglielmetti S, Taverniti V, Nizzoli G, Bosari S, Caprioli F, Rescigno M, Facciotti F. 2018. Therapeutic faecal microbiota transplantation controls intestinal inflammation through IL10 secretion by immune cells. Nat Commun 9:5184. http://dx.doi.org/10.1038/s41467-018-07359-8

24. Grander C, Adolph TE, Wieser V, Lowe P, Wrzosek L, Gyongyosi B, Ward DV, Grabherr F, Gerner RR, Pfister A, Enrich B, Ciocan D, Macheiner S, Mayr L, Drach M, Moser P, Moschen AR, Perlemuter G, 
Szabo G, Cassard AM, Tilg H. 2018. Recovery of ethanol-induced Akkermansia muciniphila depletion ameliorates alcoholic liver disease. Gut 67:891-901. http://dx.doi.org/10.1136/gutjnl-2016-313432

25. Ahmad R, Kumar B, Chen Z, Chen X, Muller D, Lele SM, Washington MK, Batra SK, Dhawan P, Singh AB. 2017. Loss of claudin-3 expression induces IL6/gp130/Stat3 signaling to promote colon cancer malignancy by hyperactivating Wnt/beta-catenin signaling. Oncogene 36:6592-6604. http://dx.doi.org/10.1038/onc.2017.259

26. Wang X, Sun G, Feng T, Zhang J, Huang X, Wang T, Xie Z, Chu X, Yang J, Wang H, Chang S, Gong Y, Ruan L, Zhang G, Yan S, Lian W, Du C, Yang D, Zhang Q, Lin F, Liu J, Zhang H, Ge C, Xiao S, Ding J, Geng M. 2019. Sodium oligomannate therapeutically remodels gut microbiota and suppresses gut bacterial amino acids-shaped neuroinflammation to inhibit Alzheimer's disease progression. Cell Res 29:787-803. http://dx.doi.org/10.1038/s41422-019-0216-x

27. Stelzner K, Herbert D, Popkova Y, Lorz A, Schiller J, Gericke M, Kloting N, Bluher M, Franz S, Simon JC, Saalbach A. 2016. Free fatty acids sensitize dendritic cells to amplify TH1/TH17-immune responses. Eur J Immunol 46:2043-53. http://dx.doi.org/10.1002/eji.201546263

28. Lowes MA, Suarez-Farinas M, Krueger JG. 2014. Immunology of psoriasis. Annu Rev Immunol 32:227-55. http://dx.doi.org/10.1146/annurev-immunol-032713-120225

29. Tonel G, Conrad C, Laggner U, Di Meglio P, Grys K, McClanahan TK, Blumenschein WM, Qin JZ, Xin H, Oldham E, Kastelein R, Nickoloff BJ, Nestle FO. 2010. Cutting edge: A critical functional role for IL-23 in psoriasis. J Immunol 185:5688-91. http://dx.doi.org/10.4049/jimmunol.1001538

30. Riol-Blanco L, Ordovas-Montanes J, Perro M, Naval E, Thiriot A, Alvarez D, Paust S, Wood JN, von Andrian UH. 2014. Nociceptive sensory neurons drive interleukin-23-mediated psoriasiform skin inflammation. Nature 510:157-61. http://dx.doi.org/10.1038/nature13199

31. Singh TP, Zhang HH, Borek I, Wolf P, Hedrick MN, Singh SP, Kelsall BL, Clausen BE, Farber JM. 2016. Monocyte-derived inflammatory Langerhans cells and dermal dendritic cells mediate psoriasis-like inflammation. Nat Commun 7:13581. http://dx.doi.org/10.1038/ncomms13581

32. Zhang X, Shi L, Sun T, Guo K, Geng S. 2021. Dysbiosis of gut microbiota and its correlation with dysregulation of cytokines in psoriasis patients. BMC Microbiol 21:78. http://dx.doi.org/10.1186/s12866-021-02125-1

33. Chen YJ, Ho HJ, Tseng CH, Lai ZL, Shieh JJ, Wu CY. 2018. Intestinal microbiota profiling and predicted metabolic dysregulation in psoriasis patients. Exp Dermatol 27:1336-1343. http://dx.doi.org/10.1111/exd.13786

34. Chen Y, Thai P, Zhao YH, Ho YS, DeSouza MM, Wu R. 2003. Stimulation of airway mucin gene expression by interleukin (IL)-17 through IL-6 paracrine/autocrine loop. J Biol Chem 278:17036-43. http://dx.doi.org/10.1074/jbc.M210429200

35. Olson CA, Vuong HE, Yano JM, Liang QY, Nusbaum DJ, Hsiao EY. 2018. The Gut Microbiota Mediates the Anti-Seizure Effects of the Ketogenic Diet. Cell 174:497. http://dx.doi.org/10.1016/j.cell.2018.06.051 
36. Wang K, Liao M, Zhou N, Bao L, Ma K, Zheng Z, Wang Y, Liu C, Wang W, Wang J, Liu SJ, Liu H. 2019. Parabacteroides distasonis Alleviates Obesity and Metabolic Dysfunctions via Production of Succinate and Secondary Bile Acids. Cell Rep 26:222-235 e5. http://dx.doi.org/10.1016/j.celrep.2018.12.028

37. English J, Jr., Bonner J, Haagen-Smit AJ. 1939. Structure and Synthesis of a Plant Wound Hormone. Science 90:329. http://dx.doi.org/10.1126/science.90.2336.329

38. Siracusa R, Impellizzeri D, Cordaro M, Gugliandolo E, Peritore AF, Di Paola R, Cuzzocrea S. 2018. Topical Application of Adelmidrol + Trans-Traumatic Acid Enhances Skin Wound Healing in a Streptozotocin-Induced Diabetic Mouse Model. Front Pharmacol 9:871. http://dx.doi.org/10.3389/fphar.2018.00871

39. Snekvik I, Nilsen TIL, Romundstad PR, Saunes M. 2019. Metabolic syndrome and risk of incident psoriasis: prospective data from the HUNT Study, Norway. Br J Dermatol 180:94-99. http://dx.doi.org/10.1111/bjd.16885

40. Setty AR, Curhan G, Choi HK. 2007. Obesity, waist circumference, weight change, and the risk of psoriasis in women: Nurses' Health Study II. Arch Intern Med 167:1670-5. http://dx.doi.org/10.1001/archinte.167.15.1670

41. Armstrong AW, Read C. 2020. Pathophysiology, Clinical Presentation, and Treatment of Psoriasis: A Review. JAMA 323:1945-1960. http://dx.doi.org/10.1001/jama.2020.4006

42. Bravo A, Kavanaugh A. 2019. Bedside to bench: defining the immunopathogenesis of psoriatic arthritis. Nat Rev Rheumatol 15:645-656. http://dx.doi.org/10.1038/s41584-019-0285-8

43. Zhu B, Wang X, Li L. 2010. Human gut microbiome: the second genome of human body. Protein Cell 1:718-25. http://dx.doi.org/10.1007/s13238-010-0093-z

44. Liu Y, van Bennekom EO, Zhang Y, Abee T, Smid EJ. 2019. Long-chain vitamin K2 production in Lactococcus lactis is influenced by temperature, carbon source, aeration and mode of energy metabolism. Microb Cell Fact 18:129. http://dx.doi.org/10.1186/s12934-019-1179-9

45. Depommier C, Everard A, Druart C, Plovier H, Van Hul M, Vieira-Silva S, Falony G, Raes J, Maiter D, Delzenne NM, de Barsy M, Loumaye A, Hermans MP, Thissen JP, de Vos WM, Cani PD. 2019. Supplementation with Akkermansia muciniphila in overweight and obese human volunteers: a proofof-concept exploratory study. Nat Med 25:1096-1103. http://dx.doi.org/10.1038/s41591-019-0495-2

\section{Figures}


Figure 1: The severity of psoriasis-like phenotype was companied with the changes of intestinal microorganisms in $2 \mathrm{M}$ and $6 \mathrm{M}$ K14-VEGF mice

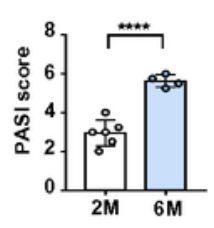

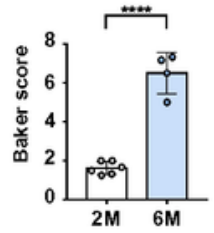

Ear
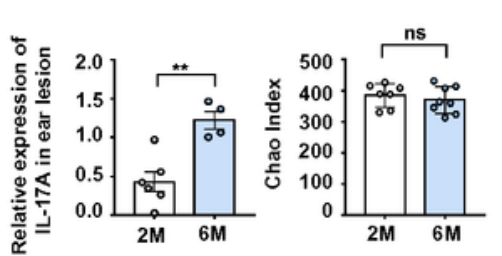

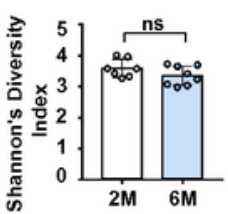

I Prevotella

F
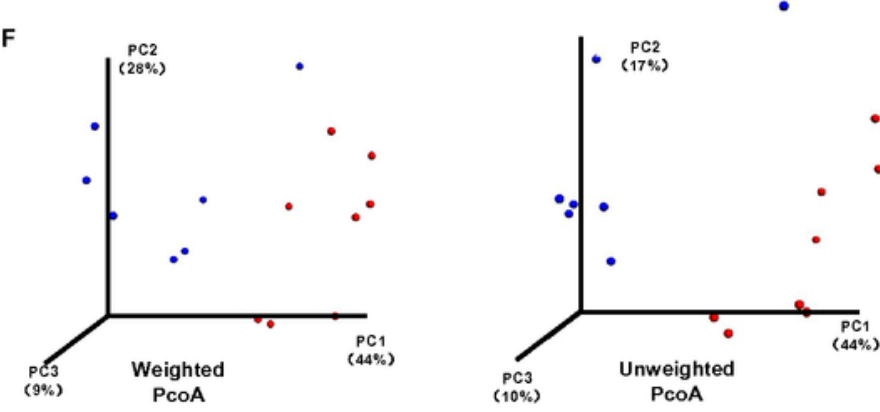

H

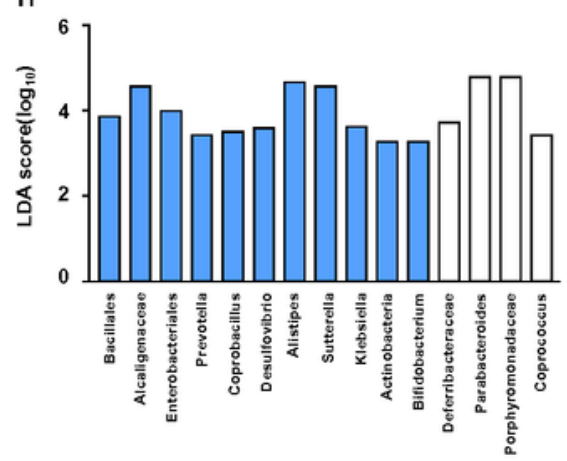

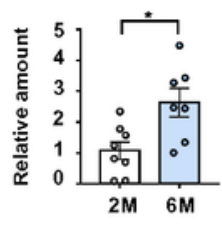

J

Parabacteroides distasonis

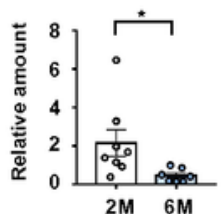

G

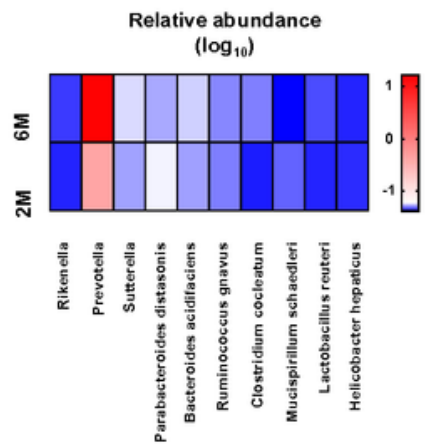

$\square$ High in 6M

$\square$ High in $2 \mathrm{M}$

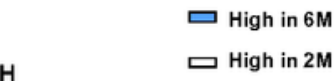

$2 \mathrm{M} 6 \mathrm{M}$

A. Psoriasis Area Severity Index (PASI) score of ear in $2 \mathrm{M}$ and $6 \mathrm{M}$ mice. B. Pathological score of ear sections using the Baker scoring system. C. Relative expression levels of IL-17A in the ear of $2 \mathrm{M}$ and $6 \mathrm{M}$ mice. D. Total richness of intestinal microbiota was measured by Chao Index. E. Bacterial diversities were measured by the Shannon's Index. F. Principal coordinates analysis of weighted (left) and unweighted (right) UniFrac distance based on $16 \mathrm{~s}$ rDNA profiling of feces from $2 \mathrm{M}$ and $6 \mathrm{M}$ mice. G. Taxonomic distributions of bacteria from fecal 16S rDNA sequencing data. $\mathrm{H}$. Results of LEfSe analysis showing bacteria, at the lowest taxonomic level, that were significantly different in abundance in $2 \mathrm{M}$ and $6 \mathrm{M}$ mice. $I$ and $\mathrm{J}$. Fecal contents of $2 \mathrm{M}$ and $6 \mathrm{M}$ mice were analyzed for Prevotella and Parabacteroides distasonis colonization by qPCR. Data presented as mean \pm SEM on relevant graphs. * p $\leq 0.05 ; * * p \leq 0.01 ; * * * p \leq 0.005$ (MannWhitney test, two-tailed)

\section{Figure 1}

"See image above for figure legend" 
Figure 2: Co-housing with 6M K14-VEGF mice aggravated the psoriasis-like phenotype of 2 M K14-VEGF mice by changing the composition of intestinal microbiota
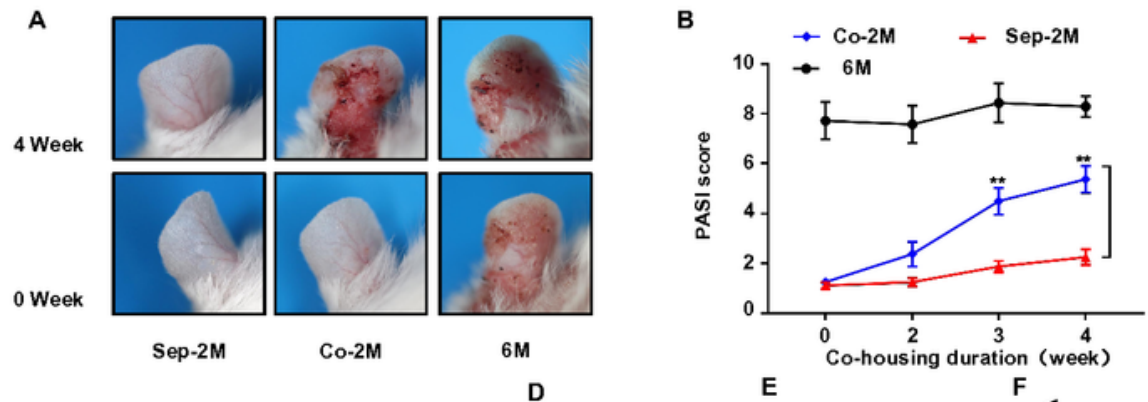

C

D

E

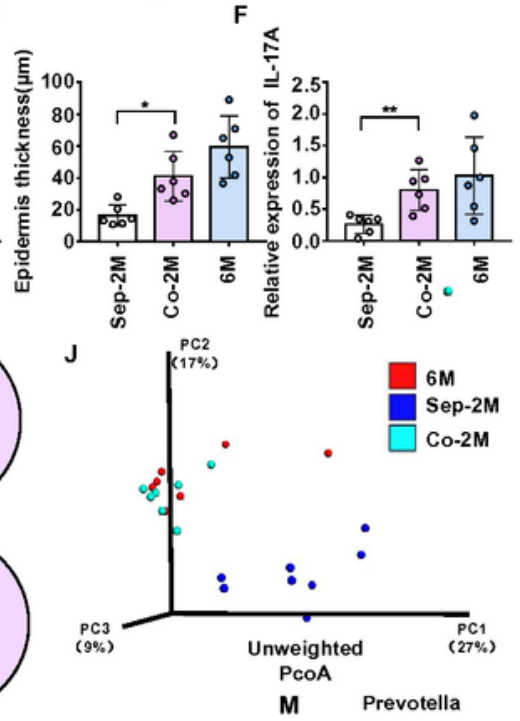

G

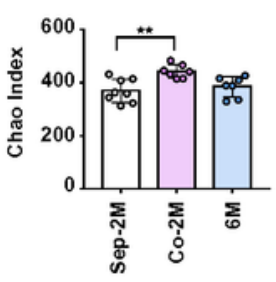

H

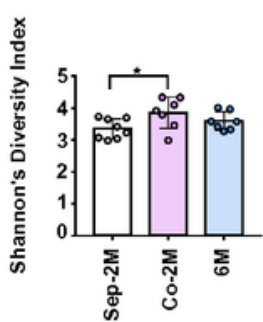

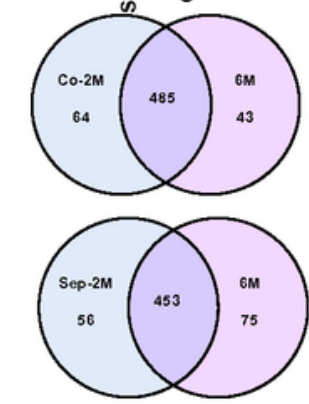

$\square$ Abundance high in Co-2M

$\mathbf{K}$

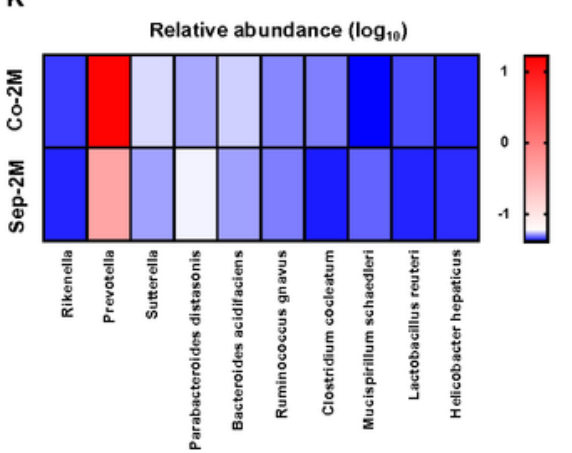

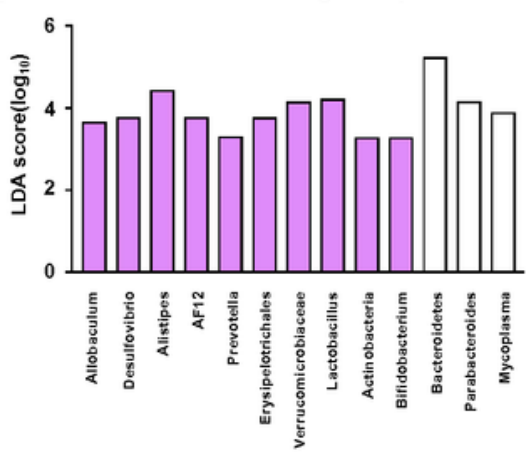

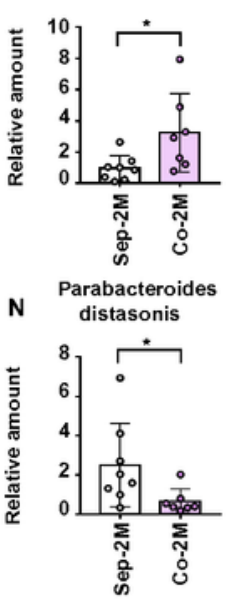

A. Macroscopic characteristics of the ears of Sep-2M Co-2M and 6M mice in 0 week and 4 week. B. PASI score of ear in of Sep-2M Co-2M and $6 \mathrm{M}$ mice from 0 week to 4 week. C. Representative H\&E staining of ears (Scale bars: $50 \mu \mathrm{m}$ ). D. Pathological score of ear sections using the Baker scoring system. E. Average epidermal thickness. F. Relative expression levels of IL-17A in the ear. G. Total richness of intestinal microbiota was measured by Chao Index. H. Bacterial diversities were measured by the Shannon's Index. I. Venn diagrams

showing the numbers of shared and unique OTUs detected in Sep-2M Co-2M and $6 \mathrm{M}$ mice. J. Principal coordinates analysis of weighted (left) and unweighted (right) UniFrac distance. K. Taxonomic distributions of bacteria. L. Results of LEfSe analysis showing bacteria, at the lowest taxonomic level, that were significantly different in abundance in Sep-2M and Co-2M mice. M and N. Fecal contents of Sep-2M and Co-2M mice were analyzed for Prevotella and Parabacteroides distasonis colonization by qPCR. Data presented as mean \pm SEM on relevant graphs. * p $\leq 0.05 ; * * \mathrm{p} \leq 0.01 ; * * * \mathrm{p} \leq 0.005$ (Mann-Whitney test, two-tailed)

Figure 2

"See image above for figure legend" 
Figure 3:Co-housing with 6M K14-VEGF mice altered the composition of intestinal metabolites in $2 \mathrm{M}$ K14-VEGF mice

A

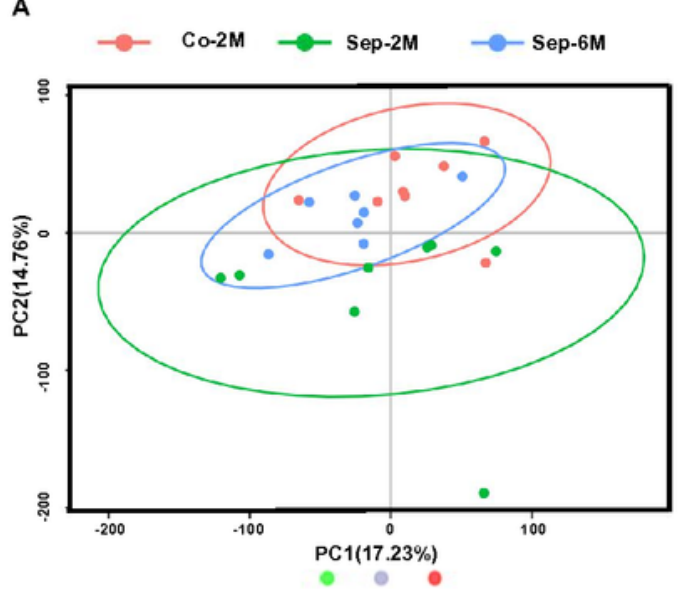

C
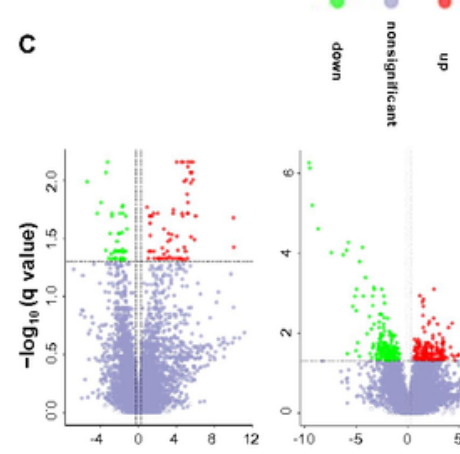

$\log 2$ (Fold change)

Sep-2M ; Sep-6M

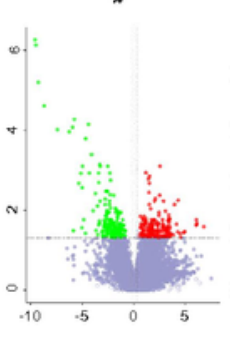

$\log 2$ (Fold change)

Sep-2M , Co-2M

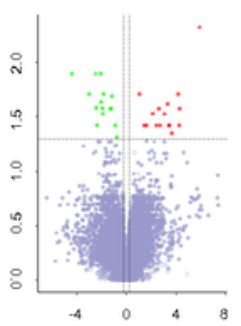

$\log 2$ (Fold change)

Co-2M : Sep-6M

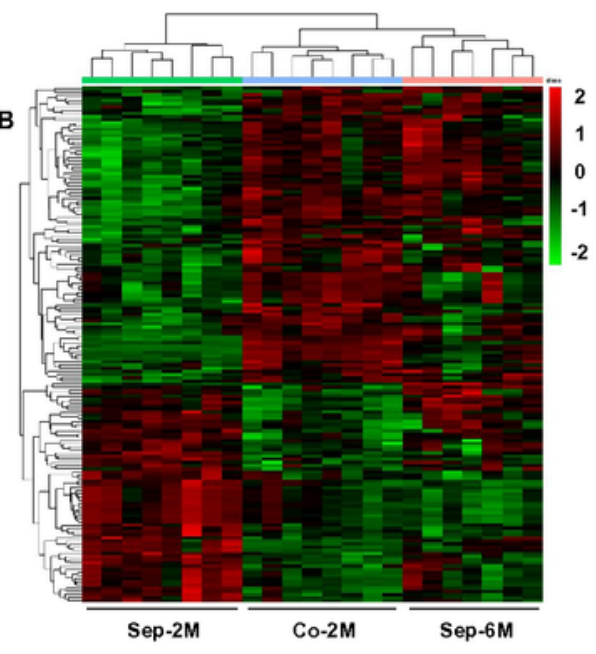

D

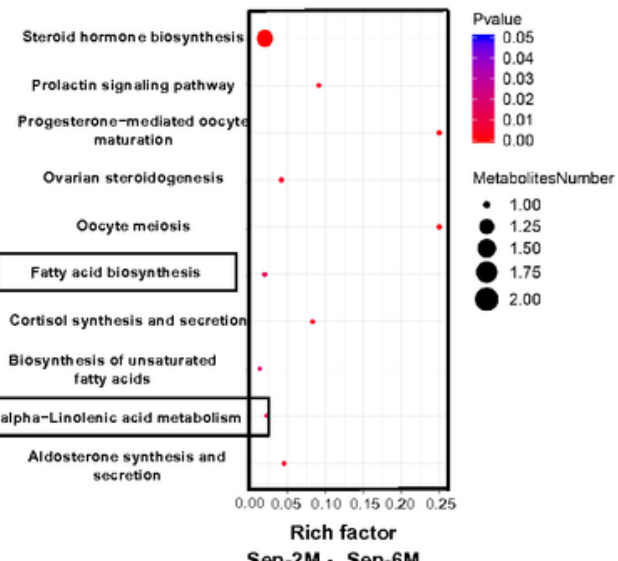

Sep-2M : Sep-6M
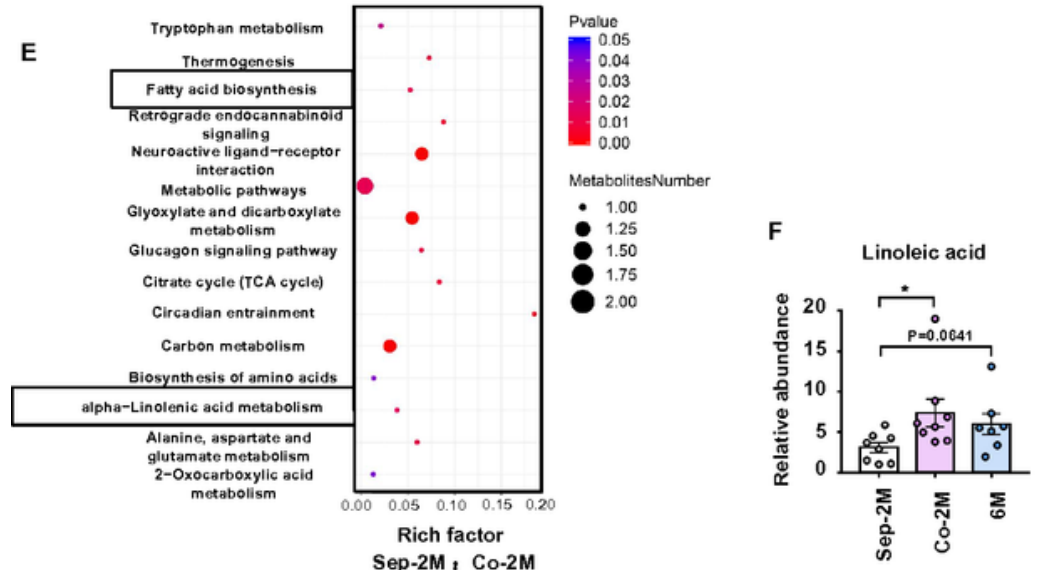

G

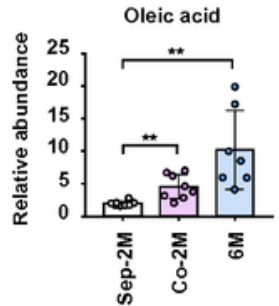

A. Principal components analysis of fecal metabolites from Sep-2M Co-2M and $6 \mathrm{M}$ mice. B. Heatmap of metabolites identified in fecal samples. C. Volcano plot of metabolites identified in fecal samples. Volcano plots are depicted with the fold change of each metabolites and the $q$ value was calculated by performing a t-test and corrected by False Discovery Rate. D and E. Pathway enrich analysis of

metabolites from Sep-2M and Sep-6M mice, and Sep-2M and Co-2M mice. F and G. Relative abundance of linoleic acid and oleic acid in fecal metabolites. Data presented as mean \pm SEM on relevant graphs. * $p \leq 0.05 ; * * p \leq 0.01 ; * * * p \leq 0.005$ (Mann-Whitney test, two-

\section{Figure 3}

"See image above for figure legend" 
Figure 4: Fecal microbiota transplantation from 6M K14-VEGF aggravated the psoriasis-like phenotype of $2 \mathrm{M} \mathrm{K14-VEGF} \mathrm{mice} \mathrm{and} \mathrm{increased} \mathrm{the} \mathrm{infiltration} \mathrm{of}$

A

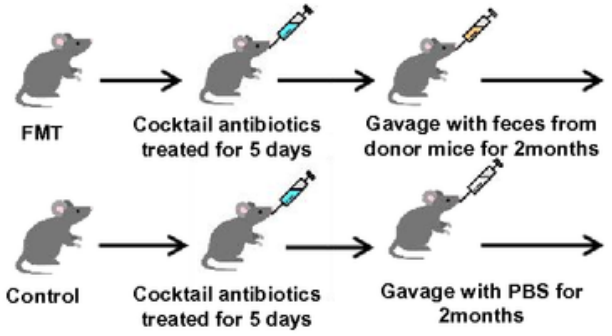

C

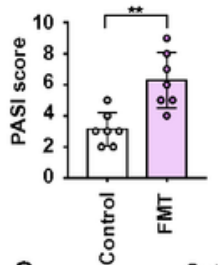

G
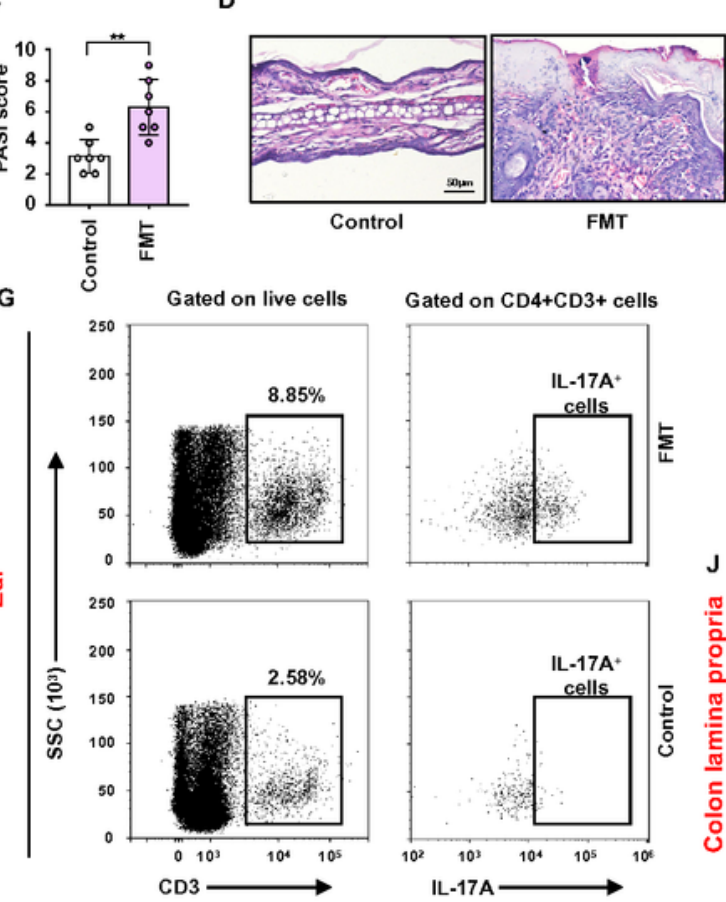

Th17 in ears

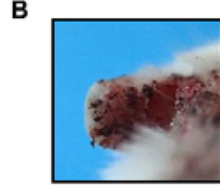

Donor

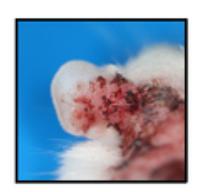

FMT

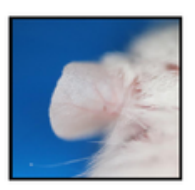

Control
E

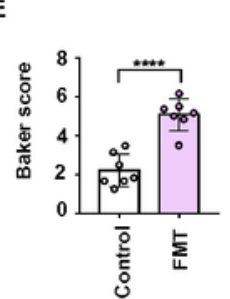

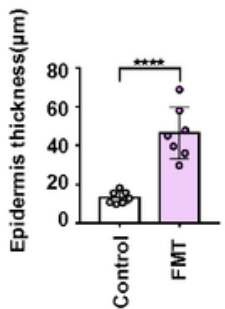
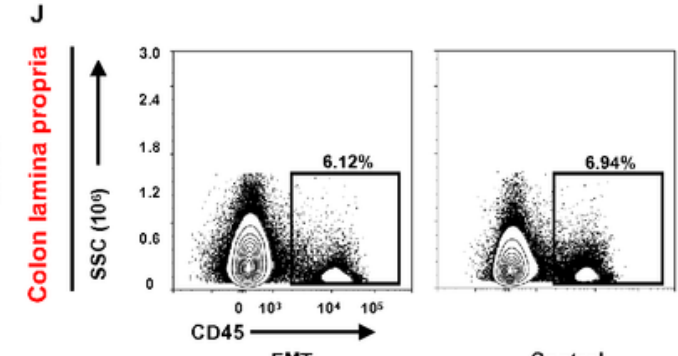

FMT

Control

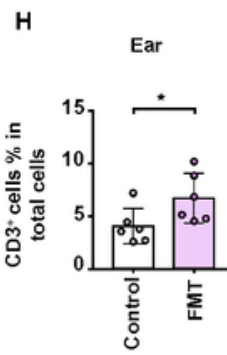

I

K

Colon

Lamina propria
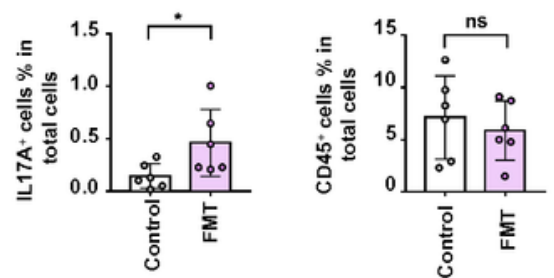

A. Scheme of the experimental design. B. Macroscopic characteristics of the ears in FMT, Control and Donor mice. C. PASI score of ear in FMT and Control mice. D. Representative H\&E staining of ears (Scale bars: $50 \mu \mathrm{m}$ ). E. Pathological score of ear sections using the Baker scoring system. F. Average epidermal thickness. G. Analysis of T cells and Th17 cells (CD4+ IL-17+) by flow cytometry in ears. H.

Percentage of T cells in total cells. I. Percentage of Th17 cells in total cells. J. Analysis of immune cells (CD45+) by flow cytometry in colon lamina propria. K. Percentage of $\mathrm{CD}^{*} 5^{*}$ cells in total cells. Data presented as mean $\pm \mathrm{SEM}$ on relevant graphs.*p $\leq 0.05 ; * * \mathrm{p} \leq$ $0.01 ; * * \mathrm{p} \leq 0.005 ; * * * \mathrm{p} \leq 0.001$ (Mann-Whitney test, two-tailed).

\section{Figure 4}

"See image above for figure legend" 
Figure 5:Fecal microbiota transplantation from 6M K14-VEGF mice altered the composition of intestinal metabolism in 2M K14-VEGF mice

A
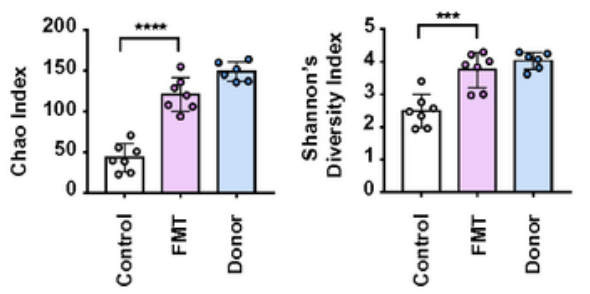

E

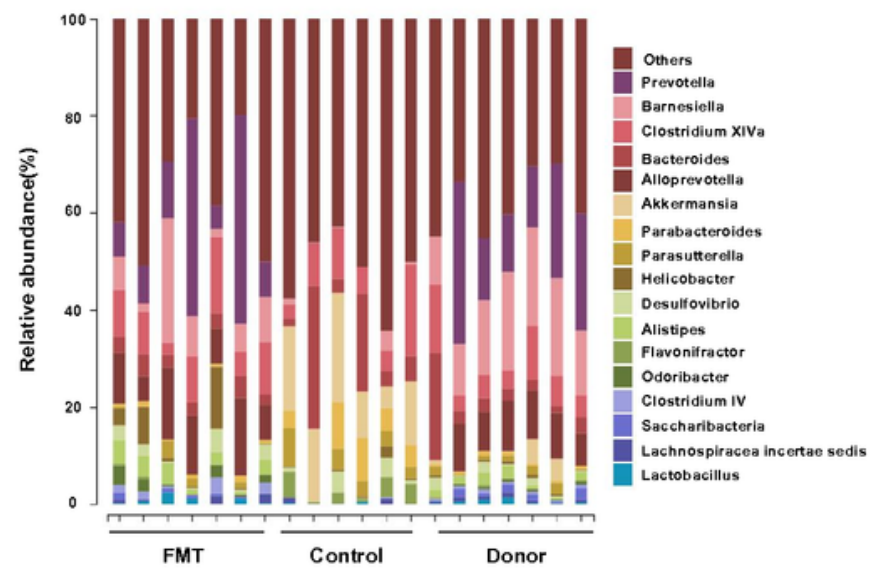

H

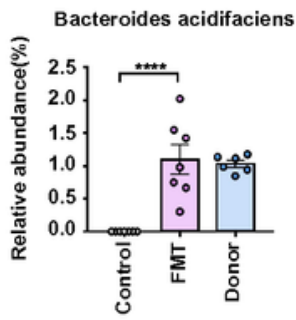

I

Alloprevotella rava

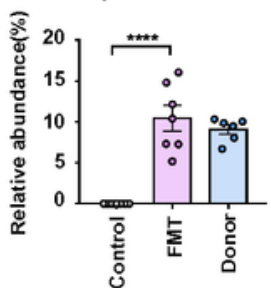

C
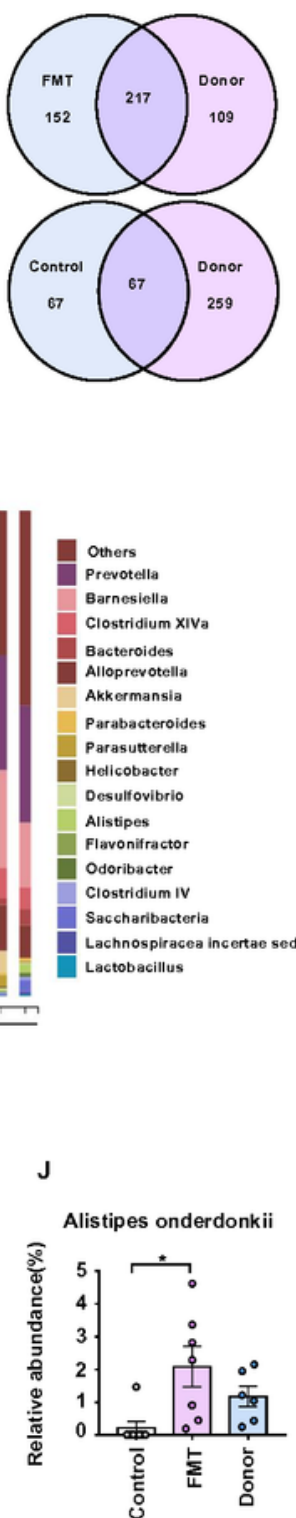

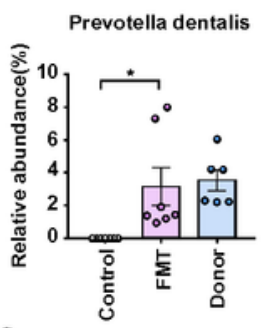

Parabacteroides distasonis

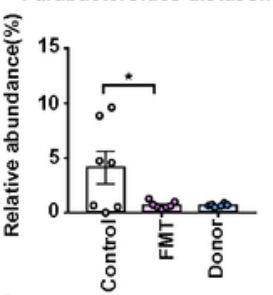

K

D $\quad$ FMT

Donor
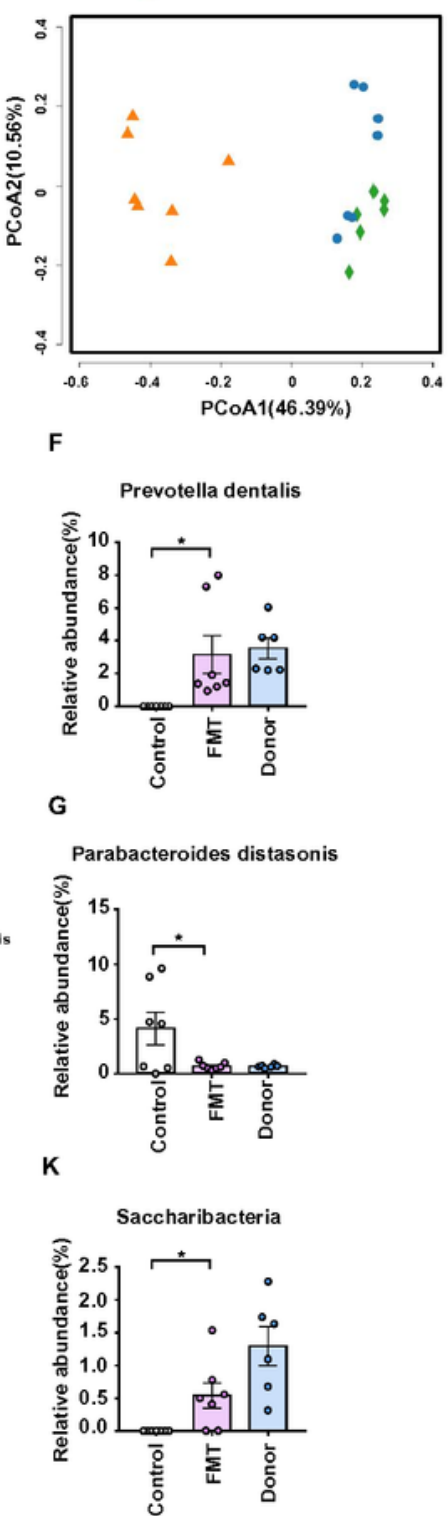

A. Total richness of intestinal microbiota was measured by Chao Index. B. Bacterial diversities were measured by the Shannon's Index. C. Venn diagrams showing the numbers of shared and unique OTUs detected in FMT, Control and Donor mice. D. Principal coordinates analysis of weighted (left) and unweighted (right) UniFrac distance. E. Taxonomic distributions of bacteria. F-K. Fecal contents in FMT,

Control and Donor mice were analyzed for Prevotella dentalis, Bacteroides acidifaciens, Alloprevotella rava, Alistipes onderdonkii

, Saccharibacteria and Parabacteroides distasonis colonization by $16 \mathrm{~S}$ microbial sequencing. Data presented as mean $\pm \mathrm{SEM}$ on relevant graphs. $* \mathrm{p} \leq 0.05 ; * * \mathrm{p} \leq 0.01 ; * * * \mathrm{p} \leq 0.005 ; * * * * \mathrm{p} \leq 0.001$ (Mann-Whitney test, two-tailed).

\section{Figure 5}

"See image above for figure legend" 
Figure 6:Fecal microbiota transplantation from 6M K14-VEGF mice altered the composition of intestinal metabolism in 2M K14-VEGF mice

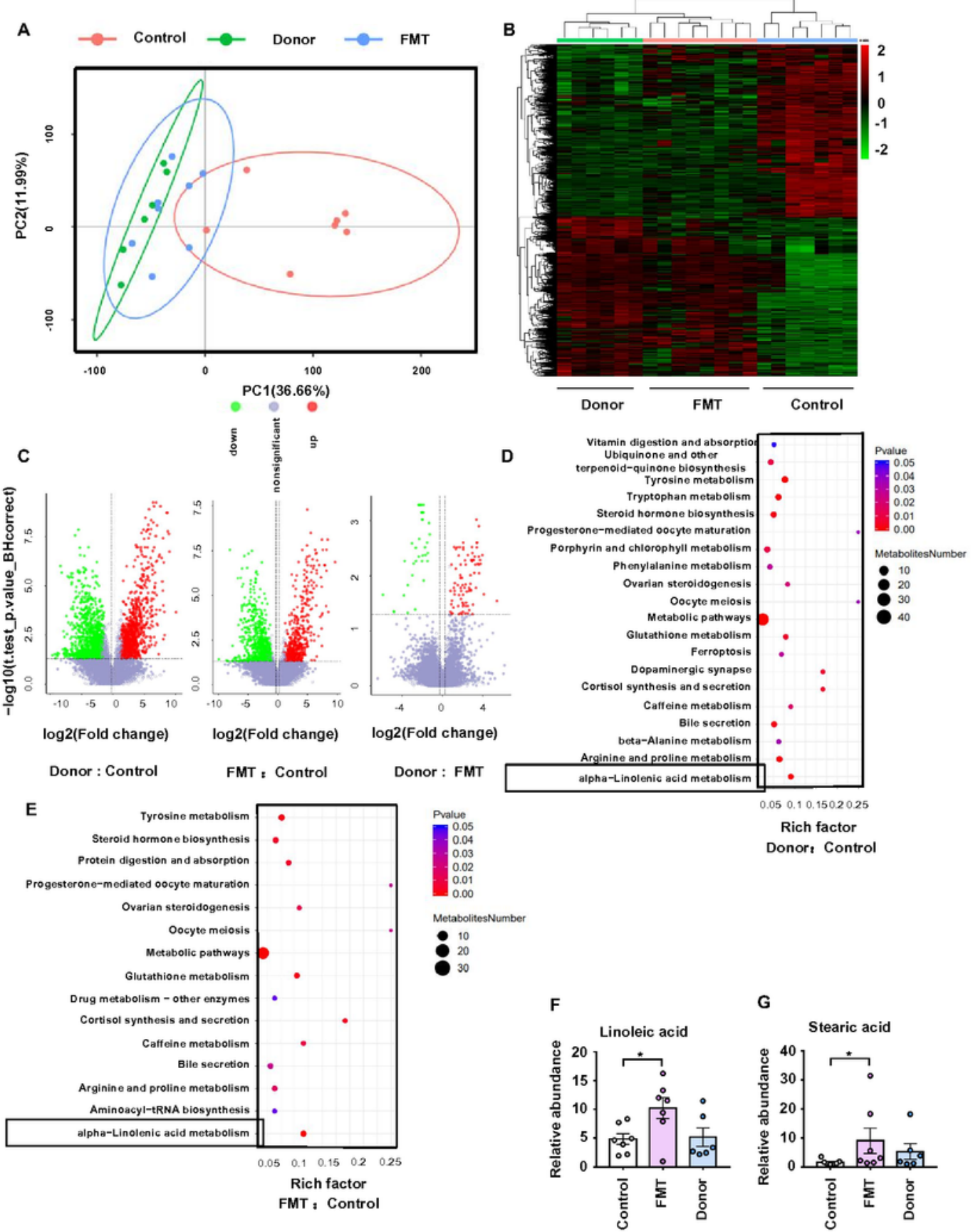

A. Principal components analysis of fecal metabolites from FMT, Control and Donor mice. B. Heatmap of metabolites identified in fecal samples. C. Volcano plot of metabolites identified in fecal samples. Volcano plots are depicted with the fold change of each metabolites and the $q$ value was calculated by performing a t-test and corrected by False Discovery Rate. $D$ and E. Pathway enrich analysis of metabolites from Donor and Control mice, and FMT and Control mice. F and G. Relative abundance of linoleic acid and stearic acid in fecal metabolites. Data presented as mean \pm SEM on relevant graphs. * p $\leq 0.05 ; * * p \leq 0.01 ; * * * p \leq 0.005$ (Mann-Whitney test, twotailed).

\section{Figure 6}

"See image above for figure legend" 
Figure 7: Administration of free fatty acid exacerbated the pathogenesis of psoriasis of 2M K14-VEGF mice and promoted the differentiation of Th17 in DLN as well as increased the infiltration of moDDCs and Th17 in ears

A
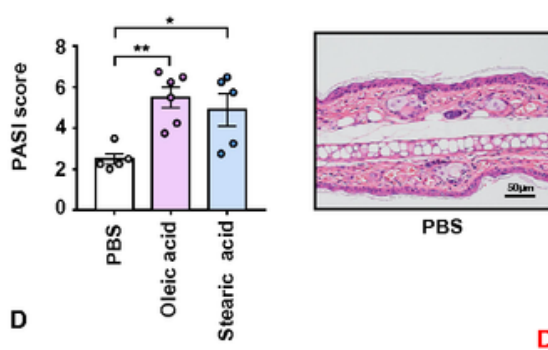

DLN

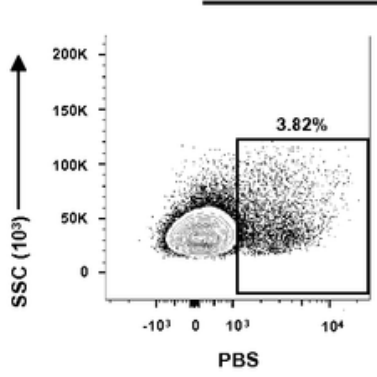

Gated on $\mathrm{CD}^{+}{ }^{+} \mathrm{CD}^{+}$cells

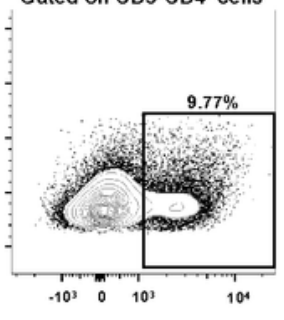

Oleic acid

Ear

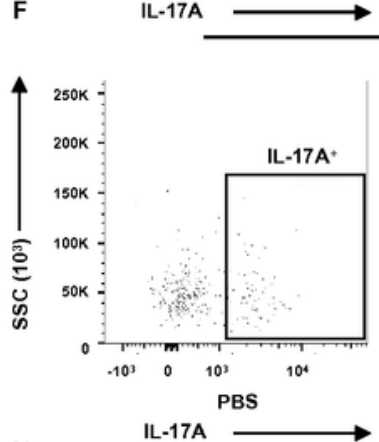

H

Monocytes (T1)

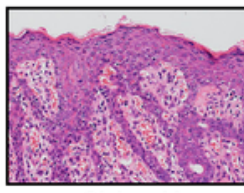

Oleic acid

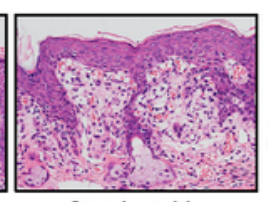

Stearic acid
C
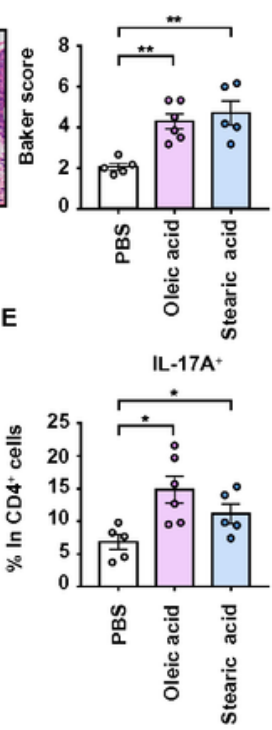

G

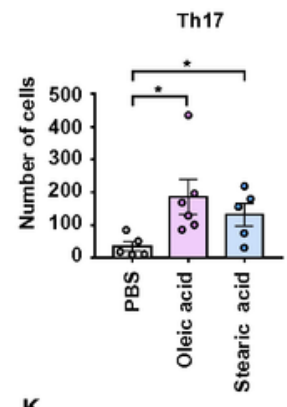

K

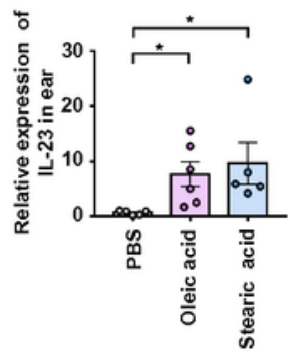

A. PASI score of ear in PBS, Oleic acid and Stearic acid group mice. B. Representative H\&E staining of ears (Scale bars: $50 \mu \mathrm{m})$. C. Pathological score of ear sections using the Baker scoring system. D. Analysis of Th17 cells (CD4+ IL-17+) by flow cytometry in DLN. E. Percentage of Th17 cells in CD4+ cells. F. Analysis of Th17 cells (CD4+ IL-17+) by flow cytometry in ears. G. Number of $\mathrm{CD}^{+} \mathrm{IL}-17^{+}$in ears. H. Number of Monocytes in ears. I and J. Number of moDDCs in ears. K. Relative expression levels of IL-23 in the ears of PBS, Oleic acid and Stearic acid group mice. Data presented as mean \pm SEM on relevant graphs. * p $\leq 0.05 ; * * p \leq 0.01 ; * * * p \leq 0.005$ (Mann-Whitney test, two-tailed).

\section{Figure 7}

"See image above for figure legend"

\section{Supplementary Files}

This is a list of supplementary files associated with this preprint. Click to download. 
- Graphicalabstract.pdf

- Supplementaryfigure.pdf 